\title{
O QUE ME AFETA, ENQUANTO ORIENTADORA EDUCACIONAL, EM TEMPOS REMOTOS
}

\author{
Relatos de uma Orientadora Educacional em busca das relações de afeto que afetam \\ a si e ao outro
}

Cristiane Barroso Dias*

\begin{abstract}
RESUMO
Este trabalho está constituído de relatos de uma orientadora educacional, em tempo de pandemia provocada pela Covid-19, com intenção de destacar o olhar sensível na sua prática pedagógica fomentada pela busca por melhorias de vida. O trabalho tem como objeto o encontro pessoal e social. Destaca a valorização de vozes do cotidiano escolar remoto com respaldo no fazer com. Traz argumentos que embasam as relações que nos afetavam antes da pandemia, para assim comprovar que a distância é mero detalhe quando se busca o trabalho em parceria. A parceria acontecendo, com o objetivo de tocar na subjetividade dos sujeitos envolvidos no processo de construção do conhecimento, incluindo pedagogos e alunos, evidencia o processo de entendimento dessa nova forma de encarar o mundo, já que as expectativas e realidades de vida estão imersas em perspectivas do presente, pois o futuro é incerto. Contudo, a esperança acontece através do planejamento de ações que priorizam o ser de cada sujeito.
\end{abstract}

\section{PALAVRAS-CHAVE: educação. orientação educacional. afetos. pandemia. relação.}

\begin{abstract}
This work is the report of an educational advisor, during the pandemic caused by Covid-19, with the intention of highlighting a sensitive look in the pedagogical practice promoted by the search for life improvement. The work has the objective of combining personal and social aspects. It highlights the value of voices of remote school daily lives with the support of collaborative activities. It brings arguments that are the basis of relationships that affected us before the pandemic, which proves that distance is a mere detail when looking for work in partnership. If the partnership happens, with the purpose of touching the subjectivity of those involved in the knowledge construction process, including pedagogues and students, it evidences the process of understanding this new way of facing the world, given the fact that expectations and reality are immersed in perspectives of the present, because the future is uncertain. However, hope arises through the planning of actions that prioritize each and every individual.
\end{abstract}

KEYWORDS: education. educational advising. affection. pandemic. relationships.

\section{Introdução}

O NAIEFE é parte do fazer da Secretaria de Educação, buscando pensar o aluno como um sujeito social em seu todo para assim propiciar uma aprendizagem escolar e de vida para o mesmo.

* Pedagoga formada pela UFF, com especialização em "Profissionais da escola e as Práticas Curriculares" (UFF) e em Psicopedagogia (UNIPLI). Orientadora Educacional, município de Maricá, através do NAIEFE (Núcleo de Atenção e Integração do Educando, Família e Escola). Núcleo da Secretaria de Educação de Maricá. Prof.a Inspetora Escolar pela Secretaria de Educação do Estado do Rio de Janeiro no município de Maricá. 
Enquanto Orientadora Educacional no NAIEFE procuro articular, junto com os colegas de núcleo e os colegas Orientadores Educacionais lotados nas unidades escolares, uma forma de planejar democraticamente a ação do Orientador Educacional com o professorado, com o alunado e com a comunidade escolar.

Em tempos de atividades remotas o Orientador Educacional, dentro de uma proposta democrática de educação popular, consegue atingir o sujeito que aprende não apenas através dos conteúdos que compõe o currículo escolar, mas sobretudo nos assuntos recorrentes a vida? Estando a vida atualmente em transformação social, econômica, ambiental...

O questionamento inicial deste texto permite o movimento de escuta sensível primeiro da prática da Orientação Educacional dentro ao NAIEFE e, logo após, ouvir os relatos de práticas de Orientadores Educacionais de unidades escolares para retornar a questão inicial e criar possibilidades sempre em favor da vida do alunado de modo a priorizar as relações que nos afetam enquanto sujeitos de aprendizagem.

$\mathrm{O}$ afeto, recorrente a prática pedagógica em tempos de pandemia causada pela COVID-19, é analisado cotidianamente através do ato de estranhar o fazer pedagógico e isso se concretiza através da minha participação primeiro escrevendo o meu relato sobre minhas relações de afeto e coletando outros de colegas e logo após como cursista no Projeto de Extensão Diálogos universidade-escola: redes de conversação e formação continuada Café com Currículo, através interroga, ora me instiga, porém me compromete a mudança.

\section{O fazer e o como fazer}

O fazer do Orientador Educacional está intrinsecamente relacionado ao ato de sentir de todos os envolvidos no processo de construção do conhecimento, inclusive o seu próprio.

O Orientador Educacional é o profissional que observa, analisa, dialoga, interage e propõe estratégias para que o aprender aconteça verdadeiramente na vida do sujeito aprendiz. Qual aprendizagem queremos para o nosso aluno? Porque sendo ele aprendiz, o conhecer se faz presente diariamente em sua vida, tendo nós, mestres, o privilégio de ajudar nesse processo de conquistas, como diz Hernandez quando enfatiza o conceito de currículo:

\footnotetext{
... procura-se transgredir a visão do currículo escolar centrada nas disciplinas, entendidas como fragmentos empacotadas em compartimentos fechados, que oferecem ao aluno algumas formas de conhecimento que pouco têm a ver com os problemas dos saberes fora da Escola, que estão afastados das demandas que diferentes setores sociais propõem à instituição escolar e que têm a função sobretudo, de manter formas de controle e poder sindical por parte daqueles que se concebem antes especialistas do que como educadores. (1998, p. 12)
} 
Então eu, como OE vinculada a SME trabalho ativamente com cerca de vinte e cinco OEs lotados nas escolas da rede. O trabalho é feito em parceria através de conversas e escutas de cada realidade escolar, além de busca por ações conjuntas nas unidades com a intenção de desenvolver os assuntos escolares através de diálogo a cerca de projetos. Escuto o colega, entendo sua lógica e trocamos vivencias para que o trabalho pedagógico articulado com as legislações e ações do município de Maricá seja possível e provável.

A Orientação Educacional no NAIEFE e na escola se completam na medida que atendem o aluno e às suas necessidades e isso vai muito além do conteúdo curricular. O acompanhamento do planejamento é constante e em tempos de pandemia, provocada pela COVID-19, se dá através dos meios tecnológicos (telefone, computador, internet...). Neste processo de longe fisicamente, mas perto diariamente através da tecnologia, foi possível perceber que o trabalho em parceria e de forma coletiva é difícil mas o melhor caminho. Dentro do NAIEFE os pensamentos ora se complementam ora se divergem e viver isso, em prol da proposta de trabalho coletivo, é uma busca frequente.

Além disso, percebo que cada Orientador que dialogo está imerso em situações pessoais que muitas vezes não o permite a continuidade no planejamento, seja a ansiedade, uma doença em família, filhos em idade escolar... Precisamos olhar o aluno mas também somos pessoas mergulhadas neste mesmo problema social.

É notório que o ato de escutar o outro profissional para assim entender a sua lógica é o diferencial na capacidade ímpar de concretização da prática, e àquele que escuta precisa se despir de seus preconceitos para entender o outro e assim somar com ele. É uma tarefa humilde! A Humildade vem do latim humilitas, e é a virtude que consiste em conhecer as suas próprias limitações e fraquezas e agir de acordo com essa consciência, diz a Enciclopédia Livre. Vygotsky, quando cita a zona de desenvolvimento proximal, faz com que entendamos que o outro é alguém capaz de me ajudar a ir além do que tenho no presente de conhecimento.

E é neste ponto que toco no indivíduo sem ser individualista, porque tento compreendê-lo e conhecer o que lhe move, podendo gerar assim uma relação intima de confiança e afeto. Eu sou um sujeito cheio de sentimentos que me aproximo do outro que também possui os seus sentimentos. Aí há uma troca de sensações e vivencias em prol de um outro sujeito, um terceiro sujeito, que não é eu, não é tu, é o ele, o aluno. Nesse momento pode acontecer o que Paulo Freire tanto enfatizava, a educação libertadora, a comunhão, porque o eu, o tu e o ele, se transformam em nós. 
Neste ir e vir de ideias e ações cativar o outro através da escuta não é tarefa simples, porque as vezes o outro escolhe o silêncio. Até mesmo no silêncio há comunicado, o comunicado de negar o diálogo. Neste momento faz-se prudente outra forma de agir. Conquistar o outro não é tarefa simples. Confiante no valor do trabalho pedagógico de forma coletiva e democrática cabem aos sujeitos paciência nas relações e quem sabe a história mude. Quem sabe?

Digo que me deparei com o silêncio quando proponho diálogo sobre um planejamento e a outra parte (a escola, o profissional) não responde, não troca pensares sobre. Neste momento podemos atingir o desanimo, mas a força necessária enraizada num trabalho democrático é maior e não me deixa paralisar. Algumas vezes isso aconteceu, a não resposta aos investimentos através das conversas remota. Mas como falei continuo tentando, sempre focada no alunado.

Focada na possibilidade de mudar histórias de vidas é que a cada momento, a cada instante a esperança em dias melhores, em pessoas melhores me permite lutar através de atos de generosidade e amor. Educar para o hoje, para mudar o mundo de hoje. Formar pessoas que estejam sensíveis ao outro, conhecendo primeiramente a si para assim entender quem é e o que lhe faz feliz intimamente. Isso é possível! Isso é provável! Isso é afeto! Cito o afeto ao colega $\mathrm{OE}$, em primeiro lugar, já que preciso trabalhar junto com ele e é humano perceber quem ele é e assim poder ajudá-lo.

Certa vez, em mensagem de transmissão de texto pelo whatsapp, uma colega respondeu com um áudio com inúmeros questionamentos a cerca do nosso fazer. Ouvi, me coloquei no lugar dela e respirei para assim prosseguir e explicar a situação do pedido. O pedido era a listagem de alunos que não estavam acompanhando as atividades remotas. Após o ocorrido esperei e dialoguei com outros pares e assim aconteceram reuniões posteriores de forma online que responderam aos questionamentos de outrora. Então não é possível responder tudo na hora, já que estamos aprendendo juntos a lidar com essa nova realidade. Precisamos reinventar a prática renovando a teoria como afirma Boaventura: $O$ que estou propondo é um duplo procedimento: ampliar o presente e contrair o futuro. $(2007$, p. 38)

Mas enfim, o nosso trabalho fluiu e está fluindo de forma muito positiva através de nossos encontros nada virtuais, digo que são reais porque a distância é um detalhe quando caminhamos juntos através das ideias. Estou aprendendo cada vez mais. E isso é notório quando neste final de semestre em diálogo com uma colega $\mathrm{OE}$ de uma escola que atende o 
segundo segmento do Ensino Fundamental comentei que estava preocupada com nossos alunos adolescentes e que gostaria de articular algo para eles. Após falarmos bastante sobre o assunto sugeri a colega que desenvolvesse um vídeo sobre. A mesma no início disse não que não sabia fazer, mas insisti e no último dia do semestre me apresentou um vídeo lindo com um depoimento encantador de uma aluna em tempos remotos. Ganhei meu maior presente, ser presença na vida da OE e da menina. É disso que falo quando expresso que precisamos tocar no indivíduo sem sermos individualistas.

Espero que através da minha prática a vida se renove e a aprendizagem seja algo degustado pelo aluno e por todos nós profissionais deste processo de forma ampla e harmoniosa. Quando sinto que aprendo o saber não é um mero conteúdo escolar, é um universo novo que se aproxima de mim, me envolve ao ponto de gerar em mim uma nova existência,porque é capaz de transformar a minha essência, sendo nós, alunos ou profissionais, porque em tempos de ações remotas todos estamos nos reinventando.

Então trago relatos de três colegas Orientadores Educacionais que fazem parte do grupo ao qual estou responsável pelo acompanhamento de ações e fomentos. São eles: Claúdia, Clícia e Mário. Esses relatos foram apresentados em live do Projeto de Extensão Café com Currículo, edição - Cyber Café: Tecendo saberes: docência e currículos em tempos de Pandemia (https://youtu.be/b0rn6cGfw4E) da UERJ/ FFP, ao qual estou participando em tempos de atividades remotas, como citado anteriormente. Seguem os relatos:

\section{$I^{\circ}$ Relato de Claúdia Cristina, Orientadora Educacional da E. M. Alfredo Nicolau:}

Sou Claudia Cristina, Orientadora Educacional no município de Maricá - RJ, atuando no momento na Escola Municipal Alfredo Nicolau, onde tenho a honra de conviver com uma maravilhosa equipe. Nesse espaço micro da educação maricaense temos tido a oportunidade de refletir sobre nossos alunos, seus conflitos, anseios e necessidades, e buscamos exercer nossas funções em colaboração mútua, para que a razão de nossas intenções, nossos alunos, se desenvolvam da melhor forma possível!

Acreditamos no fazer pedagógico amparado pelo cuidado e afetividade, que busca a valorização das diferenças, pautado em ações comprometidas com o bem estar físico e mental, onde os sentimentos diversos sejam bem tratados. Queremos um clima positivo e favorável para o desenvolvimento das meninas e meninos de nossa instituição. Assim, em nossos planejamentos, a questão empatia, afetividade e relacionamento, aluno e professor, aluno com aluno, são sempre discutidos. Nossa equipe de professores, reconhecem essas necessidades peculiares da profissão que exercemos, valores que se faltar, corremos riscos de engessar todo o processo ensino aprendizagem.

No exercício da minha função, tenho tido, especialmente nesse momento difícil a qual estamos vivendo, muita preocupação com a temática sentimentos. Para tanto tenho feito trabalhos constantes com o grupo de alunos que atendo, onde tenho abordado semanalmente um 
tipo de sentimento, nesse diálogo, mostro o limite saudável dos sentimentos, e deixo alertas para a reflexão da família, no sentido de perceber quando a situação está carecendo atenção específica. A abordagem segue da indicação de um livro digital que trata o assunto, com orientação para compartilhamento em família.

O olhar sobre a criança e suas possíveis necessidades emocionais muito nos interessa, pois como sabemos sentimentos positivos favorecem o bom andamento da aprendizagem, a boa convivência consigo e com o outro, vai além do fator desenvolvimento intelectual, em nossa escola nos sentimos responsáveis pelo desenvolvimento social e emocional de nossos alunos. A percepção de qualquer situação que foge do padrão emocional próprio para a faixa etária que atendemos, nos deixa em alerta. Temos tido resultados satisfatórios e motivadores, nos dando a certeza de estarmos no caminho certo em nossas ações.

\section{II ${ }^{0}$ Relato de Clícia, Orientadora Educacional da E. M. Pindobas:}

Sou Clícia Moraes, Orientadora Educacional da E. M. Pindobas no município de Maricá. Nós estamos nesse momento de afastamento social, de aulas remotas, trabalhando a afetividade dos alunos da maneira que estamos encontrando porque neste momento estamos abalados emocionalmente e isso não é diferente dos nossos alunos. Eu enquanto Orientadora Educacional montei um projeto na escola chamado "Juntos mesmo de longe", semanalmente eu mando propostas para as famílias de algum tipo de atividade que os familiares façam juntos desde contação de história para assistirem juntos falando sempre de sentimentos, principalmente de amor de afeto de carinho, enfim da importância do estar juntos nesse momento, como pequenos jogos, desenhos, enfim tem sido as mais diversas propostas que eu tenho enviado. Tenho proposto também visitas online a museus. Assim que eu tenho trabalhado aqui na escola e o retorno tem sido muito positivo das famílias. Além disso tem o acompanhamento pessoal através do whatsapp. Como a nossa escola é pequena o acompanhamento individual é possível. É dessa maneira que a gente tem procurado trabalhar.

\section{III ${ }^{\circ}$ Relato de Mário, Orientador Educacional da E. M. Oswaldo Lima:}

Eu sou o Mário, sou Orientador Educacional da E. M. Marisa Letícia e da E. M. Oswaldo Lima, tenho uma rotina pessoal muito gratificante e feliz. Eu tenho ligado para as famílias todos os dias para acompanhar o lidar com o isolamento social da quarentena. Eu tenho procurado acompanhar como elas estão se saindo e lidando com tudo isso, pois é uma rotina muito nova para todos. As famílias estão agradecendo muito a preocupação, o carinho, o cuidado e o zelo com elas, porque as vezes é difícil ter pessoas que liguem para lembrar de você, para saber como você e sua família estão. O feedback que eu tenho tido é muito gratificante e produtivo, creio ser necessário esse movimento entre escola e famílias. Sugiro quem puder fazer esse trabalho assim o faça, enquanto Orientador Educacional, porque traz uma felicidade muito grande para a gente que liga e também para quem está recebendo uma ligação nesse sentido.

\section{Laços nas ideias}

Cada fio de um laço respeita um processo de harmonia de movimento que em conformidade geram o laço em si. Assim quando eu, profissional da educação, me percebo como um fio desse laço eu compreendo que o meu movimento permite o movimentar de um outro fio e desse compasso iremos harmoniosamente cuidar do que é meu de responsabilidade e de ocupação, mas acima de tudo, agir em parceria como outro fio podendo assim transformar fios- 
soltos em um laço que abraça um lindo buquê de flores. Assim deve ser o trabalho da Orientação Educacional na busca pelo abraçar de vidas que dependendo do processo de construção de conhecimento florirá.

Ainda conto dois acontecimentos ocorridos antes da Pandemia que resgatam a afetividade do cotidiano vivido por mim enquanto profissional do NAIEFE na Secretaria de Educação de Maricá:

\section{$1^{\circ}$ acontecimento}

Eu estava de plantão na sala do NAIFE na SME junto com duas colegas de trabalho. Realizava ações burocráticas referente ao arquivamento de informações sobre as escolas e os alunos acompanhados. No horário de $15 \mathrm{~h}$ e $30 \mathrm{~min}$ chegou em nossa sala uma colega diretora adjunta de uma das escolas da rede de ensino de Maricá. A diretora adjunta estava apresentando ansiedade e nervoso em sua fala e nas suas atitudes. A mesma narrava que uma aluna da escola estava sendo vítima de violência doméstica a cerca de dias. A vítima uma menina de 10 anos com deficiência intelectual matriculada na escola que trabalhava.

Olhei no relógio, $15 \mathrm{~h}$ e 30 , perguntei a ela onde era a escola, com a resposta verifiquei que se tratava de alguns km de onde é a sede da Secretaria onde estávamos. Perguntei logo em seguida se ela me levaria lá. A resposta positiva, então partimos para o encontro da menina.

Ao chegar era eu a ansiosa para ver a menina. Quando entrei na secretaria da escola lá eu a avistei. Uma mocinha já,negra, alta com os cabelos presos de forma irregular. Pedi para ela se levantar e olhei o seu corpo totalmente surrado. Pedi para o Conselho Tutelar ser acionado. Assim aconteceu. A guarda municipal também encontrava-se presente.

Ouvimos coletivamente a aluna: eu, o Representante do Conselheiro Tutelar, a Diretora Escolar, a Diretora Adjunta e a Orientadora Educacional da escola. Enfim, decidimos em comum realizar uma ata in loco e o Conselho Tutelar, junto com a Guarda Municipal, levarem a aluna para os procedimentos cabíveis. Assim foi feito.

Voltei para minha rotina, para minha casa encontrar minha família no meu horário habitual, pensando eu que isso não fosse possível inicialmente ao ouvir a diretora adjunta, entretanto não duvidei em nenhum momento do que tinha que realizar independente da distância.

Os dias passaram. Minha Gerente de trabalho pelo NAIEFE foi solicitada a participar de uma audiência pública no Fórum da cidade e eu fui a acompanhando. Quando cheguei lá 
(para minha surpresa) o nome da menina desse relato foi citado. Pensei: "Não posso me calar!"

Quando o juiz pediu detalhes dos fatos levantei a mão e pedi para falar. Fui até a cadeira de depoimento e falei tudo o que vi.

O que nos move é a comunhão da dor de alguém que sofre. Não é possível para mim não sentir a dor ao perceber a fragilidade de alguém.

Naquele momento estavam presentes fora da sala da justiça, mas dentro do fórum os pais da menina. O Juiz decidiu mantê-la sob a guarda do estado.

\section{$2^{\circ}$ acontecimento}

Mais um dia de trabalho na rede de escolas de Maricá. Eu neste dia realizava visita numa escola no bairro de São José de Imbassaí após o acompanhamento habitual, já no final da visita, entreguei o termo que havia feito para a colega diretora assinar foi quando o celular dela tocou. Ela constatou que era uma mensagem no grupo de uma colega também diretora sobre uma aluna que estava em crise no espaço escolar. A colega pediu ajuda dos profissionais do NAIEFE. Ao voltar para a SME passei em frente a tal escola do pedido de ajuda.Parei o meu carro e fui até lá.

Ao chegar me deparei com toda a equipe diretiva tentando resolver o problema da menina. Todos pareciam comprometidos e cansados com as situações de conflitos provocados pela aluna. Ouvi todos e em seguida perguntei onde a menina estava. A diretora adjunta me mostrou.

A aluna estava sem uniforme, usando roupas curtas, no pátio da escola correndo de um lado para o outro sem destino aparente. Rindo alto e chupando o dedo.

Primeiro fiquei observando suas condutas e depois fui na direção dela. Consegui alguns minutos de sua atenção. Olhava sempre no olho dela e dizia que estava ali para ajudá-la. Não obtive muito sucesso. Ela continuou correndo e gritando. Depois conversei com a inspetora de alunos que estava ali no pátio todos os dias e pude perceber, através da sua fala, que a aluna "gostava" de um menino que estudava na sala que ficava próxima ao pátio. Entendi o porquê dela não aceitar ir para a sua sala de aula, pois a mesma ficava no andar superior e também entendi porque ela tirou a roupa do uniforme e colocou outra, para assim se sentir mais bonita e atrair o menino que estava interessada. 
Pedi para conversar como menino que ela gostava. Conversamos com ele eu e a diretora adjunta. Ótima conversa. Pedi a ajuda dele. Ele topou. Decidimos conversar com a menina: o menino que ela gostava, a diretora adjunta e eu. $\mathrm{O}$ menino falou que não namoraria alguém que não estudava e que vai para escola e não respeitava regras. A aluna ficou nervosa, chorou e voltou para a sua sala de aula.

Após este acontecimento tudo não virou um mar de paz e amor, mas outros pares entraram neste processo de resgate da aluna e sobre o gostar dela, o foco se voltou para outro amor.

\section{Considerações Finais}

Esses relatos do cotidiano dentro e fora dos tempos de Pandemia perpassaram neste texto com a intenção de destacar a mesma escuta sensível e o olhar observador que acontecem desde que estejamos atentos na busca pela reinvenção do mundo a partir de nós em espaços públicos, na escola pública, com ou sem muros, na proposta de trabalho da Orientação Educacional.

A Orientação Educacional é o espaço na escola destinado ao pensar crítico sobre o cotidiano do alunado e de todos os envolvidos no fazer pedagógico, sendo assim, principalmente no momento atual, precisamos ainda mais focar em práticas de construção de pensamento crítico e desconstrução de conceitos preestabelecidos. $\mathrm{O}$ ato de reflexão precisa acontecer de forma contínua buscando o entendimento de quem somos, isso está intimamente relacionado às nossas ações dentro ou fora do espaço escolar e envolve as relações de afeto. É possível!

As relações de afeto me constrói em quando sujeito social e podem me impulsionar a sair da estabilidade ao qual eu construí e que me acomoda. Se mover possibilita interação como outro e entendimento de mim mesmo de modo a continuar no movimento em prol de mudanças sociais e culturais. A Orientação Educacional priva pela construção do saber de forma coletiva, com interação.

Trago por fim, para concluir este artigo, Anísio Teixeira, pensador da escola pública no Brasil, pois suas ideias transcorrem por décadas e podemos afirmar que as mesmas são presentes e necessárias na nossa práxis hoje: A escola tem que dar ouvidos a todos e a todos servir. Será o teste de sua flexibilidade (In PRADO, 2020). 


\section{Referências Bibliográficas}

HERNÁNDEZ, Fernando. Transgressão e mudança na educação. Os projetos de trabalho. São Paulo: Editora Artes Médicas Sul, 1998.

PRADO, Ricardo. Anísio Teixeira, o guerreiro da sala de aula. Nova Escola, 2000. Disponível em: <https://novaescola.org.br/conteudo/1672/anisio-teixeira-o-guerreiro-da-sala-deaula>. Acesso em: 13 ago. 2020.

SANTOS, Boaventura de Souza. Renovar a teoria crítica e reinventar a emancipação social; tradução de Mouzar Benedito, São Paulo: Boitempo, 2007.

VYGOTSKY, L. S. A formação social da mente: o desenvolvimento dos processos psicológicos superiores; organizadores Michel Cole, tradução José Cipolla Neto, Luis Silveira Menna Barreto, Solange Castro Afeche. São Paulo: Martins Fontes, 1991. 